\section{Actinic prurigo in Scandinavian adolescent successfully treated with cyclosporine $A$}

\author{
Jan C. Sitek \\ Department of Dermatology, Oslo \\ University Hospital, Norway
}

\begin{abstract}
Actinic prurigo is a pruritic sun-induced dermatosis classified among the immunologically mediated photodermatoses. The disease is a well-known entity among Native Americans and in Central and South America, however rare in Caucasians with only a few reports from Australia, Britain and France. We report the first case of actinic prurigo in a Scandinavian patient, responding favorably to systemic treatment with cyclosporine A.
\end{abstract}

\section{Case Report}

An 11-year old Norwegian girl presented with a long-standing itchy rash resistant to topical and systemic steroids. She was otherwise healthy. Physical examination revealed a centro-facial rash consisting of erythematous papules, excoriations and crusts on an erythematous basis (Figure 1A) and excoriated papules on her upper extremities and chest. Cheilitis and conjunctivitis were absent.

Standard laboratory investigations, complement factors and autoantibodies were all within normal range. Porphyrin screening was negative. Phototesting showed reduced and normal MED for UVA and UVB, respectively.

Skin biopsy showed focal para- and hyperkeratosis, mild acanthosis and a perivascular predominantly mononuclear infiltrate (Figure 2). Direct immunofluorescence staining for $\operatorname{IgA}, \operatorname{IgG}, \operatorname{IgM}$ and C3 were negative. Human leucocyte antigen (HLA) typing detected the DRB $1 * 0407$ subtype.

Clinical presentation and additional investigations strongly indicated actinic prurigo (AP).

Sunblocks, potent steroids and antihistamines were ineffective. UV desensitization therapy was considered but not feasible for practical reasons. Treatment with hydroxychloroquine and subsequently tetracyclines, both for several months, yielded no improvement. Cyclosporine A was initiated, bringing the disease in partial remission within a few weeks. After 4 months followup itch and non-facial lesions were practically absent, with the exception of hypopigmented scars to her arms (Figure 1C). Facial involvement was considerably milder (Figure 1B).

The mother of the patient has given her written informed consent for publication of all material in this manuscript, including the photographs.

\section{Discussion and Conclusions}

AP is an immunologically mediated photodermatosis primarily described in Amerindians and people of Central and South American descent with frequent familial occurrence and early-childhood
Correspondence: Jan Cezary Sitek, Department of Dermatology, Oslo University Hospital, Post box 4950 Nydalen, 0424 Oslo, Norway.

Tel.: +4723072430. E-mail: jsitek@ous-hf.no

Key words: Photodermatosis; immunosuppression; pediatric dermatology.

Contributions: JCS has had full access to all patient data, made all contributions to the conception of this case report and drafted and approved the version to be published.

Conflict of interest: the author declares no conflict of interest

Received for publication: 16 January 2017. Accepted for publication: 16 May 2017.

This work is licensed under a Creative Commons Attribution-NonCommercial 4.0 International License (CC BY-NC 4.0).

\section{(C) Copyright J.C. Sitek, 2017}

Licensee PAGEPress, Italy

Dermatology Reports 2017; 9:7050

doi:10.4081/dr.2017.7050

onset. ${ }^{1}$ In Caucasians AP occurs sporadically, typically starts in adolescence and to a lesser extent present conjunctivitis and cheilitis. $^{2-4}$ The disease has previously not been described in Scandinavian patients. AP normally manifests in spring as an itchy papular dermatitis in sun-exposed areas. Coalescing patches, with vesicular and erosive areas may develop and non-exposed skin may be affected. HLA DRB $1 * 0407$ subtype is strongly associated with AP in populations of both Caucasian ${ }^{3}$ and Centraland South-American descent. ${ }^{5}$ The
A

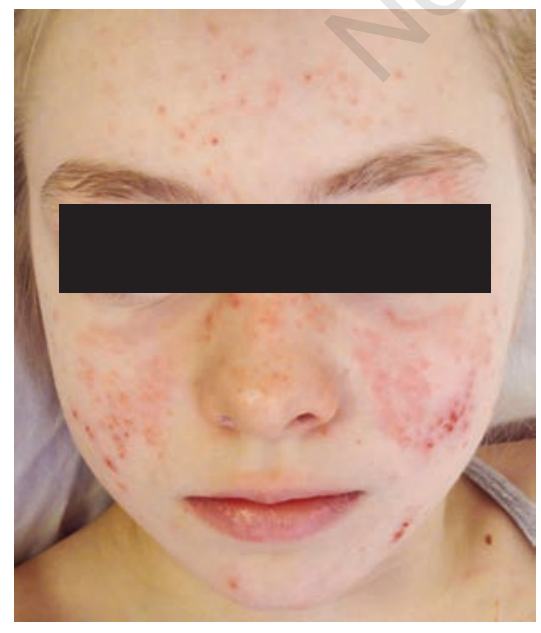

B

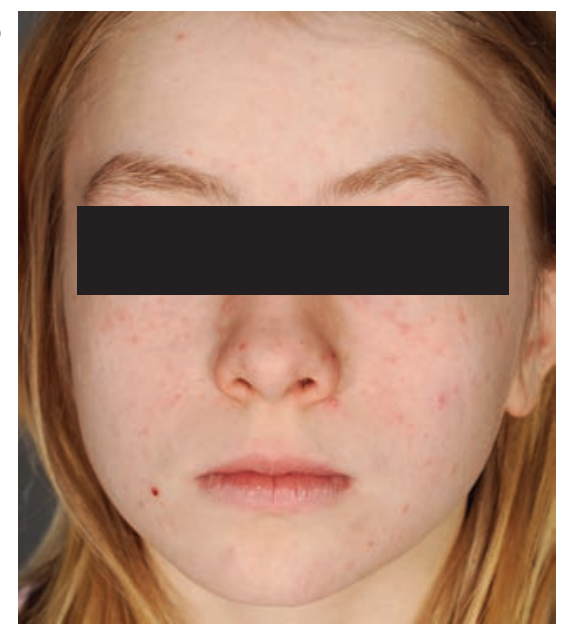

C

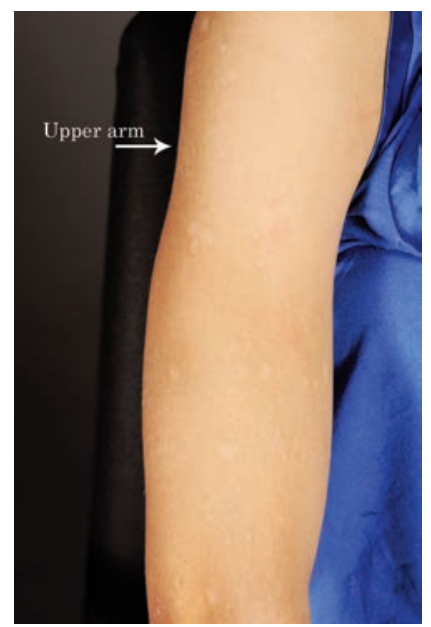

Figure 1. Actinic prurigo: A) facial rash before cyclosporine A treatment; B) facial rash at 4 months follow-up with cyclosporine A treatment showing significant improvement; C) upper extremity at 4 months follow-up with cyclosporine A treatment showing remission of activity and post-inflammatory hypopigmented scars. 


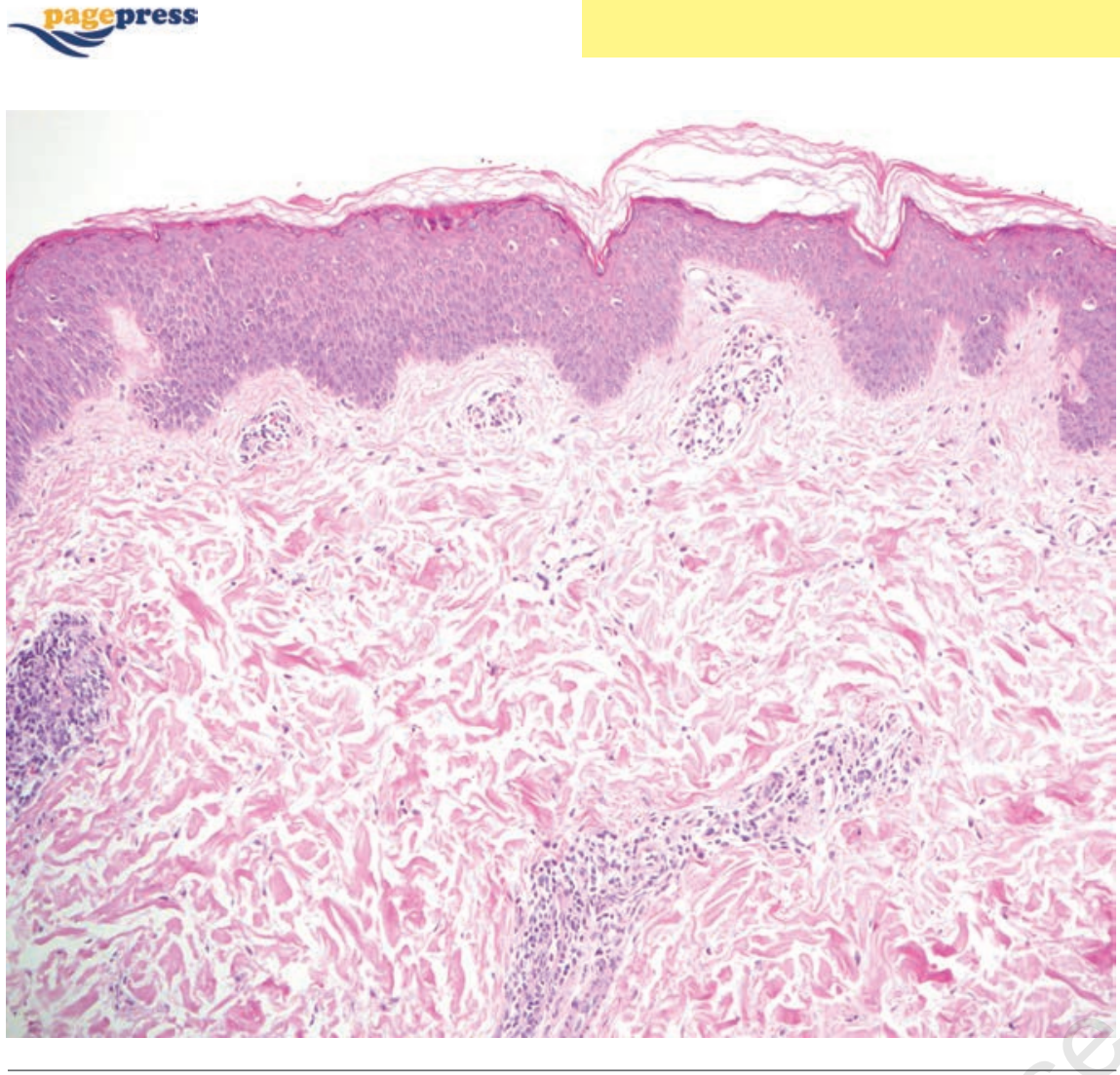

Figure 2. Histopathology (H\&E) from upper arm/elbow. Focal para- and hyperkeratosis, mild acanthosis and a perivascular, predominantly lymphocytic infiltrate.

DRB1*0407 subtype is not associated with polymorphic light eruption (PLE) and may aid in the distinction between PLE and AP. ${ }^{3}$

Treatment of AP includes sun-protective measures, topical steroids, antihistamines and preventive UVB therapy. Systemic therapies, including antimalarials, tetracyclines and systemic steroids, are often ineffective or not suitable for longterm treatment. Thalidomide is generally recommended as the treatment of choice in recalcitrant cases, however the risk of peripheral neuropathy and teratogenesity limit its usage. ${ }^{1}$

Cyclosporine $\mathrm{A}$ is an immunosuppressive drug exerting anti-pruritogenic effects, possibly through inhibition of T-cell activity and proliferation, and migration of eosinophilic granulocytes to the skin. ${ }^{6} \mathrm{UV}$ exposed skin normally exhibits a decrease of epidermal Langerhans cells. In AP the number of Langerhans cells is maintained, referred to as UV resistance. Partial decrease in epidermal Langerhans cells in AP patients treated with cyclosporine A has been observed. Whether these observations indicate a direct effect on the migration of Langerhans cells or suppression of the UV resistance remains elusive. ${ }^{7}$

Our patient is the first ethnic Scandinavian reported with AP. She had no atopy, which is frequently recorded in Caucasians with AP. She carried the HLA the Norwegian population (T. Egeland, 2016, personal communication) as comDRB $1 * 0407$ subtype, present in only $1 \%$ of pared to frequencies of $18-60 \%$ in Amerindians and Colombian sub-populations. ${ }^{5}$ Cyclosporine A is generally omitted as a therapy option for AP in publications on photodermatoses, including a recent review paper regarding photodermatoses in children. ${ }^{1}$ We advocate cyclosporine $\mathrm{A}$ as a suitable treatment alternative in AP patients demanding systemic intervention.

\section{References}

1. Chantorn R, Lim HW, Shwayder TA. Photosensitivity disorders in children: part I. J Am Acad Dermatol 2012;67:1093.e1-18.

2. Crouch R, Foley P, Baker C. Actinic prurigo: a retrospective analysis of 21 cases referred to an Australian photobiology clinic. Australas J Dermatol 2002;43:128-32.

3. Grabczynska SA, McGregor JM, Hawk $\mathrm{JL}$, et al. Actinic prurigo and polymorphic light eruption: common pathogenesis and the importance of HLADR4/DRB1*0407. Br J Dermatol 1999;140:232-6.

4. Batard ML, Bonnevalle A, Thomas P, et al. Caucasian actinic prurigo: 8 cases observed in France. $\mathrm{Br} \mathrm{J}$ Dermatol 2001;144:194-6.

5. Suárez A, Valbuena $\mathrm{MC}$, de Porras Quintana L, et al. Association of HLA subtype DRB10407 in Colombian patients with actinic prurigo. Photodermatol Photoimmunol Photomed 2006;22:55-8.

6. Sonkoly E, Muller A, Homey B, et al. IL31: a new link between $T$ cells and pruritus in atopic skin inflammation. $\mathrm{J}$ Allergy Clin Immunol 2006;117:411-7.

7. Umaña A, Gómez A, Porras L, et al. Lymphocyte subtypes and adhesion molecules in actinic prurigo: observations with cyclosporin A. Int J Dermatol 2002;41:139-45. 